Wang, L. and Chen, Q. 2007. "Theoretical and numerical studies of coupling multizone and CFD models for building air distribution simulations," Indoor Air, 17, 348-361.

\title{
THEORETICAL AND NUMERICAL STUDIES OF COUPLING MULTIZONE AND CFD MODELS FOR BUILDING AIR DISTRIBUTION SIMULATIONS
}

\section{Wang and Q. Chen}

The Ray W. Herrick Laboratories, School of Mechanical Engineering, Purdue University, West Lafayette, Indiana, U.S.A.

Q. Chen

School of Mechanical Engineering, Purdue University, 585 Purdue Hall, West Lafayette, IN 47907-2040, USA

Tel.: (765) 496-7562

Fax: (765) 496-7534

e-mail: yanchen@purdue.edu

\begin{abstract}
Multizone network models employ several assumptions, such as uniform temperature and pressure and quiescent air inside a zone, which may lead to inaccurate results in flow calculations. These assumptions can be eliminated in the zones, where the assumptions are inappropriate, by coupling a multizone network program with a Computational Fluid Dynamics (CFD) program. Through theoretical analysis, this paper proves that the solution of air distribution by using the coupled program exists and is unique. Three possible coupling methods are then discussed in the paper. The best method is pressure-pressure coupling that exchanges pressure between the multizone and CFD since it is most stable and can always lead to a converged solution. Numerical tests were further performed to verify the theory and it demonstrated that the coupled program is able to effectively improve the accuracy of the results.
\end{abstract}

Key words: Multizone; Coupling; Computational fluid dynamics; Theoretical analysis; Air distribution; Coupling methods

\section{Practical Implications}

The results of this paper provides theoretical basis for improving the accuracy for modeling airflow and contaminant distributions in buildings. The coupled multizone and computational fluid dynamics can give high fidelity results so field measurements may not needed in the future. Designers of indoor environment in the future can use such a tool to evaluate different alternatives in design and identify the best solution for a building that can provide a healthy indoor environment.

\section{Nomenclature}

a coefficient of an unknown variable

$\mathrm{b} \quad$ source term in a mass continuity equation

$b^{\prime} \quad$ source term in the linear form of mass continuity equation for a zone in a multizone program

B $\quad$ vector of the source terms in the assembled total matrix equation for Method 1

c index of CFD zones 


\begin{tabular}{|c|c|}
\hline $\mathrm{C}$ & nonlinear flow coefficient \\
\hline $\mathbf{C}$ & coefficient matrix in an assembled total matrix equation \\
\hline $\mathbf{C}_{1}$ & coefficient matrix in the assembled total matrix equation for Method 1 \\
\hline$C$ & system equations for a CFD program \\
\hline $\mathrm{C}_{\mathrm{L}}$ & linear flow coefficient \\
\hline $\mathrm{d}$ & $\begin{array}{l}\text { difference between the local pressure of a flow path and the pressure of the zone, to } \\
\text { which the path connects }\end{array}$ \\
\hline $\mathrm{F}$ & air mass flow rate \\
\hline $\mathbf{F}$ & vector of unknown flow rates through interface paths and cells \\
\hline f & airflow rate through the face of a CFD cell, perpendicular to the flow direction \\
\hline g & acceleration of gravity \\
\hline $\mathrm{i}$ & index of the zones for a multizone program; input parameter for $C$ \\
\hline ic & index of the flow paths linking zone $\mathrm{i}$ and zone $\mathrm{c}$ \\
\hline $\mathrm{ij}$ & index of the flow paths linking zone $\mathrm{i}$ and zone $\mathrm{j}$ \\
\hline $\mathrm{j}$ & index of the zones for a multizone program \\
\hline$M$ & system equations for a multizone program \\
\hline $\mathrm{n}$ & flow exponent \\
\hline $\mathrm{p}$ & pressure at a grid point \\
\hline $\mathrm{P}$ & pressure of a zone; index of grid points or cells \\
\hline $\mathbf{P}$ & vector of unknown pressures of multizone zones and CFD cells \\
\hline$P_{d}$ & downwind total pressure of an airflow path \\
\hline $\mathrm{P}_{\mathrm{S}}$ & pressure difference due to density and elevation differences \\
\hline $\mathrm{P}_{\mathrm{u}}$ & upwind total pressure of an airflow path \\
\hline $\mathrm{P}_{\mathrm{W}}$ & pressure difference due to wind \\
\hline $\mathrm{r}$ & input parameter for $M$ \\
\hline $\mathrm{S}$ & source term \\
\hline $\mathbf{V}$ & velocity vector \\
\hline$\rho$ & air density \\
\hline$\Delta$ & difference \\
\hline$\phi$ & general variable \\
\hline$\Gamma$ & diffusion coefficient for $\phi$ \\
\hline \multicolumn{2}{|c|}{ Subscripts } \\
\hline $\mathrm{i}$ & index of the zones of a multizone program \\
\hline ic & index of the flow paths linking zone $\mathrm{i}$ and zone $\mathrm{c}$ \\
\hline $\mathrm{ij}$ & index of the flow paths linking zone $i$ and zone $j$ \\
\hline $\mathrm{j}$ & index of the zones of a multizone program; coordinate direction \\
\hline $\mathrm{k}$ & index of coupling iterations \\
\hline $\mathrm{nb}$ & neighboring \\
\hline $\mathrm{P}$ & index of grid points or cells \\
\hline
\end{tabular}

\section{Introduction}

Multizone network models (hereafter multizone) have been used as a research and design tool for over 20 years (Emmerich, 2001) for air distribution analysis, smoke controls, and etc. To achieve fast computing speed, a number of assumptions must be made regarding zone parameters and airflow characteristics. For example, multizone network models typically assume each room of a building as a zone with uniform temperature and pressure and neglect the airflow momentum preserved inside a zone. For a flow with strong momentum effect, these assumptions may compromise the accuracy of the results obtained. Murakami et al. 
(1991) noted current multizone network models fail to account for the preservation of kinetic energy of the airflow. Later, Schaelin et. al. (1993) discussed the multizone assumptions more extensively. They claimed that the local variables near the flow paths within each zone, e.g. air velocity and temperature, could have a strong influence on the multizone model predictions. Clarke (2001) also pointed out current building air flow modelling by network approach has significant limitations: because momentum effects are neglected, intra-room air flow and temperature distribution cannot be determined. More recently, Gao and Chen (2003) found that multizone models produce incorrect results in a T-junction due to the neglect of preserved momentum within a zone.

To improve the accuracy of multizone flow predictions, other airflow calculation models should be used within a zone, such as zonal models. The first zonal model was proposed by Lebrun (1970), who divided a single zone into sub-zones based on the characteristics of the main driving flows. Instead of assuming a uniform temperature, thermal stratificaiton was estimated for the zone. Since Lebrun's pioneer work, various zonal models (Inard, 1988; Li et al., 1998; Haghighat et al., 2001) have been developed for different appliations, e.g. flows with plumes, jets and boundary layers, etc. Grelat (1987), Bouia and Dalicieux (1991) and Wurtz (1995) generized the zonal models by developing a pressure zonal model. The model divides a room into sub-zones with non-uniform pressures. The pressures are then solved by imposing mass balances to each sub-zone.

Since zonal models can provide non-uniform distributions of pressures and airflow patterns, they are useful in improving the accuracy of multizone model simulations. Stewart and Ren (2003) nested zonal models within a multizone model - COMIS (Feustel, 1999) and developed a new program called CoWZ, for 'COMIS with sub-zones'. Although CoWZ was domonstrated to be able to improve the accuracy of contaminant distributions calculated by COMIS, the zonal models of CoWZ can only be applied to single rooms with a limited set of driving forces (Ren, 2002). Based on a more robust simulation enviroment of zonal models SPARK (Buhl et al., 1993), Mora (2003a) also tried to couple zonal and multizone models. Both of Ren and Mora, however, did not resolve the problem of neglected momentum effect in multizone models. On the other hand, Musy (1999) pointed out that the pressure variable solved in zonal models is really an internal variable used to balance the flow equations, which should not be confused with the pressure variable solved in multizone models. So Mora et al. (2003b) concluded that when zonal models are coupled with multizone models, the pressure predictions by zonal models should be ignored, and only the airflows should be used at the interfaces shared by the two models. Mora et al. therefore suggested that Computational Fluid Dynamics (CFD) should be an alternative to zonal models for coupling with multizone models in building air distribution simulations.

As the most sophisticated airflow model, CFD calculates detailed spatial distributions of air velocity, temperature and contaminants by solving the governing conservation equations. While both multizone and zonal models are still under development nowadays, CFD has been successfully applied to various types of indoor airflow simulations as reviewed by Ladeinde and Nearon (1997), Emmerich (1997) and Nielson (1998).

Although the idea of the coupling of multizone and CFD in building airflow simulations was proposed farily early (Schaelin et al., 1993), literature search shows that not many coupling studies have been conducted. Schaelin et al. proposed a method called 'method of detailed flow path values', in which the perfect mixing assumptions of multizone models were remedied by provided with detailed pressures, velocities and contaminant concentrations of 
flow paths from CFD. This study, however, only implemented the coupling of contaminant concentrations and did not actually performed the coupling in airflow simulations. The coupling procedure was also an external or 'manual' iteration.

Clarke et. al (1995a) and Negrao (1998) implemented an automatic airflow coupling inside ESP-r (Clarke, 1985) with CFD. However, in their studies, different coupling methods resulted in dramatically different results for the same airflow problem, which indicated multiple solutions of airflow coupling. Bartak et al. (2002) recently refined the CFD module of ESP-r and adopted a 'conflation controller' (Beausoleil, 2000) to improve the simulation capacities of the CFD module of ESP-r. In the airflow coupling, however, the conflation controller by default only transfers the CFD-calculated airflows to the multizone model. They did not explain why the CFD-calculated pressures were not employed. Musser (2001), and Yuan and Srebric (2002) compared results from multizone and CFD programs for contaminant transport simulations. However, both of them avoided the problem of airflow coupling by using predefined airflow rates in contaminant transport simulations. Recently, Jayaraman et. al (2004) tried to develop an algorithm for airflow coupling and demonstrated the algorithm on a two-dimensinal building with a large space. Their preliminary study showed that coupling CFD to a multizone model can result in more realistic predictions of aiflow and contaminnant transport in buildings with large spaces. The details of their algorithm, however, were not provided in the literature.

Among the past coupling endeavors in building simulations, the airflow coupling of multizone and CFD models was considered the most sophisticated (Musser, 2001). The coupling is necessary for providing an accurate soultion. The question is whether a solution exists from the coupled simulation and if the solution unique. Unfortunately, not much work has been done for such theoretical analyses. On the other hand, in the coupled building energy and CFD simulations, Clarke et. al (1995b) proved the coupling solution existence by analyzing a super-matrix of the coupling. Zhai (2003) investigated the solution uniqueness by performing parametric analysis for both energy simulation and CFD models. Inspired by their studies, this paper investigates whether a coupled multizone and CFD program can have a solution for an airflow problem and if the solution is unique.

\section{Theoretical Analysis}

Basic equations and coupling principles

In order to analyze if a coupled multizone and CFD simulation has a solution and if the solution is unique, the analysis should start from the fundamentals of the coupling. The idea

of multizone-CFD coupling is to apply a multizone program to most zones of a building while applying a CFD program to the zones where the multizone assumptions are not appropriate. Figure 1 illustrates the coupling schematic for natural ventilation in a portion of a three-story building with an atrium. The atrium is so large that the homogeneous assumption is inappropriate and Zone $\mathrm{c}$ is thus chosen as the CFD zone while the remaining zones are modeled with the multizone program. Although the zones modeled with the multizone program are connected to Zone c by paths at their interfaces, the equations solved by the multizone and CFD programs are quite different from each other. 


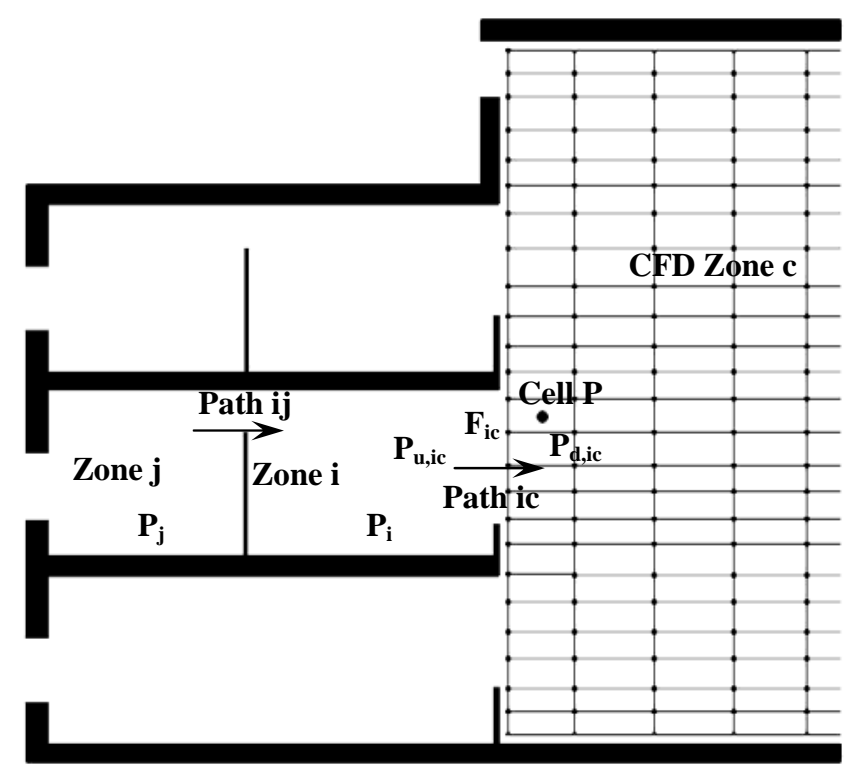

Figure 1 Coupling schematic in a portion of a three-story building with an atrium

If Path ij connects Zone $\mathrm{i}$ and Zone $\mathrm{j}$ and $\mathrm{F}_{\mathrm{ij}}$ is defined as the airflow rate through Path $\mathrm{ij}, \mathrm{F}_{\mathrm{ij}}$ is normally calculated in a multizone program by a power-law function of the pressure drop across Path ij,

$$
\mathrm{F}_{\mathrm{ij}}=\mathrm{C}_{\mathrm{ij}}\left|\Delta \mathrm{P}_{\mathrm{ij}}\right|^{\mathrm{n}_{\mathrm{ij}}}=\mathrm{C}_{\mathrm{ij}}\left|\mathrm{P}_{\mathrm{i}}-\mathrm{P}_{\mathrm{j}}+\mathrm{P}_{\mathrm{S}, \mathrm{ij}}+\mathrm{P}_{\mathrm{W}, \mathrm{ij}}\right|^{\mathrm{n}_{\mathrm{ij}}}
$$

Suppose Path ic connects Zone i for the multizone program and Zone c for the CFD program, and the flow rate through Path ic is $F_{i c}$, a mass continuity equation under steady state condition can be obtained for Zone $\mathrm{i}$ by the multizone program

$\sum_{j} F_{i j}-F_{i c}=b_{i}$

In the CFD program, a set of partial differential governing equations for mass, momentum, and energy conservation are solved. The equation can be written for steady state flow in a general form

$$
\nabla(\rho \mathbf{V} \phi)-\Gamma_{\phi} \nabla^{2} \phi=\mathrm{S}_{\phi}
$$

where $\phi$ can be 1 for mass continuity, $U_{j}$ for air velocity component in the $\mathrm{j}$ direction $(\mathrm{j}=\mathrm{x}$, $\mathrm{y}, \mathrm{z}$ ), and $\mathrm{T}$ for temperature. With the SIMPLER algorithm (Patankar, 1980) the mass continuity equation actually becomes a pressure equation. If Path ic has $\mathrm{n}$ discrete grid points and we focus only on the grid point $\mathrm{P}$ (or cell $\mathrm{P}$ ), the pressure equation for point $\mathrm{P}$ can be written in the following linear form

$$
\sum \mathrm{a}_{\mathrm{nb}} \mathrm{p}_{\mathrm{nb}}-\mathrm{a}_{\mathrm{P}} \mathrm{p}_{\mathrm{P}}+\mathrm{f}_{\mathrm{P}}=\mathrm{b}_{\mathrm{P}}
$$

A linear form can also be obtained for non-linear Eq. (2) in a multizone program 
$\sum_{j} C_{L, i j}\left(P_{j}-P_{i}\right)-F_{i c}=b_{i}^{\prime}$

where $b_{i}^{\prime}=b_{i}-\sum_{j} C_{L, i j}\left(P_{S, i j}+P_{W, i j}\right)$, by defining a linear flow coefficient

$\mathrm{C}_{\mathrm{L}, \mathrm{ij}}=\frac{\mathrm{F}_{\mathrm{ij}}}{\Delta \mathrm{P}_{\mathrm{ij}}}$

Eqs. (4) and (5) show mathematically that, $F_{i c}$ and $f_{P}$, are the only linkages between the multizone and CFD equations. It is thus important to know how they are calculated in both of the programs and how they are related to each other.

A CFD program calculates

$f_{P}=C_{L, P}\left(P_{u, i c}-p_{P}\right)$

where $P_{u, i c}=P_{i}+d_{i c}$, which is the upwind total pressure of Path ic if airflow is from Zone $i$ to Zone c. In a multizone program

$\mathrm{F}_{\mathrm{ic}}=\mathrm{C}_{\mathrm{L}, \mathrm{ic}}\left(\mathrm{P}_{\mathrm{u}, \mathrm{ic}}-\mathrm{P}_{\mathrm{d}, \mathrm{ic}}\right)$

where $\mathrm{C}_{\mathrm{L} \text {,ic }}$ is the linear flow coefficient and $\mathrm{P}_{\mathrm{d} \text {,ic }}$ is the average downwind total pressure for Path ic. Eq. (8) is actually the integral form of Eq. (7) and it comes

$\mathrm{F}_{\mathrm{ic}}=\sum_{\mathrm{P}=1}^{\mathrm{n}} \mathrm{f}_{\mathrm{P}}$

An assembled total matrix equation can then be obtained by applying Eqs. (4) and (5) to all the zones in Figure 1.

$\mathbf{C P}+\mathbf{F}=\mathbf{B}$

where $\mathbf{P}$ is the unknown pressure vector of zones and cells and $\mathbf{F}$ is the vector of unknown flow rates at interface paths and cells. To ensure that Eq. (10) is closed, two coupling principles must be followed.

- $\quad$ Eq. (9) should be used as the convergence criterion of the coupled simulation.

- The relationship of flow rate and pressure drop in Eq. (7) must be the known condition for each grid points of Path ic.

To implement Eq. (9) in the coupling program as the convergence criterion, a relative residue is defined by: 


$$
\frac{\sum_{\mathrm{k}=1}^{\mathrm{m}}\left(\left|\mathrm{F}_{\mathrm{ic}}-\sum_{\mathrm{P}=1}^{\mathrm{n}} \mathrm{f}_{\mathrm{P}}\right|\right)_{\mathrm{k}}}{\mathrm{F}_{\text {inf low }}} \leq \varepsilon
$$

where, $\mathrm{k}$ and $\mathrm{m}$ are the index and the total number of the interface paths respectively, $\mathrm{F}_{\text {inflow }}$ is the total inflow to the CFD zone and $\varepsilon$ is $1 \%$ in current study.

With the above two principles and Eq. (10), we can examine important parameters linking the multizone and CFD equations in the coupling.

Parameter analysis

In the coupling, the important parameters are $\mathrm{P}_{\mathrm{u}, \mathrm{ic}}, \mathrm{P}_{\mathrm{d} \text {,ic }}$ and $\mathrm{F}_{\mathrm{ic}}$ for both multizone and CFD programs. In order to make theoretical analysis on these parameters, this investigation uses the following simplifications:

- Flow coefficients, $C_{L, P}, C_{L, i j}$, and $C_{L, i c}$; the source terms, $b_{i}, b_{i}^{\prime}, d_{i c}, b_{P}$, and $\mathbf{B}$; and the coefficients, $a_{p}$ and $a_{n b}$; are constant from one coupling iteration to the next (one coupling iteration includes one call of multizone and one call of CFD).

- In the CFD calculation, the flow coefficients, $C_{L, P}$ and $a_{P}$, and the pressures, $p_{P}$ and $p_{n b}$, are uniform at Path ic.

- The derivatives of $\mathrm{P}_{\mathrm{d}, \mathrm{ic}}$ and $\mathrm{F}_{\mathrm{ic}}$ over $\mathrm{P}_{\mathrm{u}, \mathrm{ic}}$ are existent and bounded.

Although both problems formulated by multizone and CFD simulations are nonlinear, it is appropriate to assume mathematically the flow coefficients of multizone method, $\mathrm{C}_{\mathrm{L}, \mathrm{ij}}$ and $\mathrm{C}_{\mathrm{L}, \mathrm{ic}}$ as defined by Eq. (6), to be constant. This assumption is valid as long as the change of pressure difference, $\Delta \mathrm{P}$, is small from one multizone call to the next during coupled iterations. If we focus on the vicinity of $\Delta \mathrm{P}$, the flow coefficients can shift slowly with $\Delta \mathrm{P}$ so it can be considered constant. In CFD, the coefficients, $\mathrm{C}_{\mathrm{L}, \mathrm{P}}$, $\mathrm{a}_{\mathrm{P}}$ and $\mathrm{a}_{\mathrm{nb}}$, can also be assumed constant as long as the boundary conditions do not change significantly from one CFD call to the next. Technically, this can be realized in the coupling program by under-relaxing the flow coefficients in both multizone and CFD methods. On the other hand, for nonlinear problems, it is hard or sometimes impossible to conduct theoretical studies such as solution uniqueness and stability analysis. Thus, such simplifications are necessary for the nonlinear problem.

From the above simplifications, we can obtain the following relationships for a multizone program by using Eqs. (5) and (8)

$$
\begin{aligned}
& P_{d, i c}=\frac{C_{L, i c}+C_{L, i j}}{C_{L, i c}} P_{u, i c}-\frac{C_{L, i j} P_{j}-C_{L, j i} d_{i c}-b_{i}^{\prime}}{C_{L, i c}} \\
& F_{i c}=-C_{L, i j} P_{u, i c}+C_{L, i j} P_{j}-C_{L, i j} d_{i c}-b_{i}^{\prime}
\end{aligned}
$$

By using Eqs. (4), (7), (8) and (9) for a CFD program we have

$$
\mathrm{P}_{\mathrm{d}, \mathrm{ic}}=\frac{\mathrm{C}_{\mathrm{L}, \mathrm{P}}}{\mathrm{a}_{\mathrm{P}}+\mathrm{C}_{\mathrm{L}, \mathrm{P}}} \mathrm{P}_{\mathrm{u}, \mathrm{ic}}+\frac{\sum \mathrm{a}_{\mathrm{nb}} \mathrm{p}_{\mathrm{nb}}-\mathrm{b}_{\mathrm{P}}}{\mathrm{a}_{\mathrm{P}}+\mathrm{C}_{\mathrm{L}, \mathrm{P}}}
$$




$$
F_{i c}=\frac{a_{P} C_{L, i c}}{a_{P}+C_{L, P}} P_{u, i c}-\frac{C_{L, i c}\left(\sum a_{n b} p_{n b}-b_{P}\right)}{a_{P}+C_{L, P}}
$$

These equations reveal the mathematical relationships of $\mathrm{P}_{\mathrm{u}, \mathrm{ic}}, \mathrm{P}_{\mathrm{d}, \mathrm{ic}}$, and $\mathrm{F}_{\mathrm{ic}}$, which are exchanged between the two programs iteratively through boundary conditions. The existence and uniqueness of the solution to this iterative procedure can be investigated by studying the derivatives of these equations for a coupled simulation.

Solution existence and uniqueness

Zhai (2003) successfully coupled a building energy simulation program with a CFD program. A similar approach to Zhai's study is adopted here to prove the solution existence and uniqueness for a coupled multizone and CFD program. The basic idea is to analog pressure in coupled airflow simulations with air temperature in coupled energy simulations.

Applying the derivatives over $\mathrm{P}_{\mathrm{u}, \mathrm{ic}}$ for both sides of Eqs. (12)-(15), we have

$$
\begin{gathered}
\frac{\partial P_{d, i c}}{\partial P_{u, i c}}=\left\{\begin{array}{l}
\frac{C_{L, i c}+C_{L, i j}}{C_{L, i c}}-\frac{C_{L, i j}}{C_{L, i c}} \frac{\partial P_{j}}{\partial P_{i}} \text { (multizone) } \\
\frac{C_{L, P}}{a_{P}+C_{L, P}}+\frac{\sum a_{n b} \frac{\partial p_{n b}}{\partial P_{u, i c}}}{a_{P}+C_{L, P}} \text { (CFD) }
\end{array}\right\} \\
\frac{\partial F_{i c}}{\partial P_{u, i c}}=\left\{\begin{array}{l}
-C_{L, i j}+C_{L, i j} \frac{\partial P_{j}}{\partial P_{i}} \quad \text { (multizone) } \\
\frac{a_{P} C_{L, i c}}{a_{P}+C_{L, P}}-\frac{\sum a_{n b} \frac{\partial p_{n b}}{\partial P_{u, i c}}}{\left(a_{P}+C_{L, P}\right) / C_{L, i c}}(C F D)
\end{array}\right\}
\end{gathered}
$$

One of the conditions of unique solution to a steady-state airflow simulation in a multizone program is that increase of pressure in one zone should increase or maintain the net outflow to the neighboring zones. (Lorenzetti, 2002). This implies that in Figure 1, the increase of $\mathrm{P}_{\mathrm{i}}$ should increase or maintain $\mathrm{P}_{\mathrm{j}}$

$$
\frac{\partial P_{j}}{\partial P_{i}} \geq 0
$$

In a CFD program, the increase of $\mathrm{P}_{\mathrm{u}, \text { ic }}$ will increase or maintain the pressures of the nodes next to it and the flow rate through Path ic

$$
\begin{aligned}
& \frac{\partial \mathrm{p}_{\mathrm{nb}}}{\partial \mathrm{P}_{\mathrm{u}, \mathrm{ic}}} \geq 0 \\
& \frac{\partial \mathrm{F}_{\mathrm{ic}}}{\partial \mathrm{P}_{\mathrm{u}, \mathrm{ic}}} \geq 0
\end{aligned}
$$


Furthermore, $\mathrm{P}_{\mathrm{j}}$ and $\mathrm{P}_{\mathrm{u}, \mathrm{ic}}$ are calculated by multizone programs and their changes from one coupling iteration to the next can attribute to the change of the boundary pressure, $\mathrm{P}_{\mathrm{d} \text {,ic }}$ from CFD programs. So

$$
\frac{\partial \mathrm{P}_{\mathrm{j}}}{\partial \mathrm{P}_{\mathrm{i}}}=\frac{\partial \mathrm{P}_{\mathrm{j}}}{\partial \mathrm{P}_{\mathrm{u}, \mathrm{ic}}}=\frac{\partial \mathrm{P}_{\mathrm{j}} / \partial \mathrm{P}_{\mathrm{d}, \mathrm{ic}}}{\partial \mathrm{P}_{\mathrm{u}, \mathrm{ic}} / \partial \mathrm{P}_{\mathrm{d}, \mathrm{ic}}}
$$

Applying the condition of unique solution in a multizone program to Path ic of Fig. 1, we obtain

$$
\begin{aligned}
& \frac{\partial \mathrm{F}_{\mathrm{ic}}}{\partial \mathrm{P}_{\mathrm{d}, \mathrm{ic}}} \leq 0 \\
& \frac{\partial \mathrm{P}_{\mathrm{u}, \mathrm{ic}}}{\partial \mathrm{P}_{\mathrm{d}, \mathrm{ic}}} \geq 0
\end{aligned}
$$

If applying the derivative over $\mathrm{P}_{\mathrm{d} \text {,ic }}$ for both sides of Eq. (8) and also considering Eq. (21), we then get

$$
\frac{\partial \mathrm{P}_{\mathrm{u}, \mathrm{ic}}}{\partial \mathrm{P}_{\mathrm{d}, \mathrm{ic}}} \leq 1
$$

We then apply Eqs. (21) - (23) for Path ij in Fig. 1

$$
\frac{\partial \mathrm{P}_{\mathrm{j}}}{\partial \mathrm{P}_{\mathrm{i}}}=\frac{\partial \mathrm{P}_{\mathrm{j}}}{\partial \mathrm{P}_{\mathrm{u}, \mathrm{ic}}} \leq 1
$$

Combining Eqs. (18) and (24), one can obtain for multizone programs

$$
0 \leq \frac{\partial \mathrm{P}_{\mathrm{j}}}{\partial \mathrm{P}_{\mathrm{i}}} \leq 1
$$

Applying Inequalities (19) and (25) to Eqs. (16) and (17), finally we have

$$
\begin{aligned}
& \frac{\partial P_{d, i c}}{\partial P_{u, i c}}=\left\{\begin{array}{lc}
\left(1, \frac{C_{L, i c}+C_{L, i j}}{C_{L, i c}}\right] & \text { (multizone) } \\
{\left[\frac{C_{L, P}}{a_{P}+C_{L, P}}, 1\right)} & (C F D)
\end{array}\right\} \\
& \frac{\partial F_{i c}}{\partial P_{u, i c}}=\left\{\begin{array}{lc}
{\left[-C_{L, i j}, 0\right)} & (\text { multizone }) \\
\left(0, \frac{a_{P} C_{L, i c}}{a_{P}+C_{L, P}}\right] & (C F D)
\end{array}\right\}
\end{aligned}
$$

Note that Eqs. (26) and (27) exclude the situation when $\partial \mathrm{P}_{\mathrm{d}, \mathrm{ic}} / \partial \mathrm{P}_{\mathrm{u}, \mathrm{ic}}=1$ and $\partial \mathrm{F}_{\mathrm{ic}} / \partial \mathrm{P}_{\mathrm{u}, \mathrm{ic}}=0$, which indicates that $F_{\text {ic }}$ is constant/known so the coupled simulation is not needed for Path ic. 
Eqs. (26) and (27) illustrate how $\mathrm{P}_{\mathrm{d} \text {,ic }}$ and $\mathrm{F}_{\text {ic }}$ change with $\mathrm{P}_{\mathrm{u}, \mathrm{ic}}$ in multizone and CFD programs. The parenthesis indicates an open side of an interval and the bracket means closed side, e.g., in Eq. (26), for multizone method $1<\left(\partial \mathrm{P}_{\mathrm{d}, \mathrm{ic}} / \partial \mathrm{P}_{\mathrm{u}, \mathrm{ic}}\right) \leq\left(\mathrm{C}_{\mathrm{L}, \mathrm{ic}}+\mathrm{C}_{\mathrm{L}, \mathrm{ij}}\right) / \mathrm{C}_{\mathrm{L}, \mathrm{ic}}$. The solution existence and uniqueness of a coupled simulation can then be studied through Eqs. (26) and (27).

The $\mathrm{P}_{\mathrm{d}, \mathrm{ic}}-\mathrm{P}_{\mathrm{u}, \text { ic }}$ relations are plotted in Figure 2. If there is a solution for the coupled multizone and CFD program, the two curves will intersect as shown in the figure. Eq. (26) shows that the derivative of $P_{d, i c}$ over $P_{u, i c}$ for multizone calculation is always greater than unity, while that of CFD is less than unity as shown in Figure 2a. Therefore, both curves can at least intersect at one point, which indicates at least one coupling solution exists.

A similar analysis can also be applied to the relations of $\mathrm{F}_{\mathrm{ic}}-\mathrm{P}_{\mathrm{u}, \mathrm{ic}}$, which are omitted here due to limited space available in this paper. The next concern then will be whether the solution is unique or not.

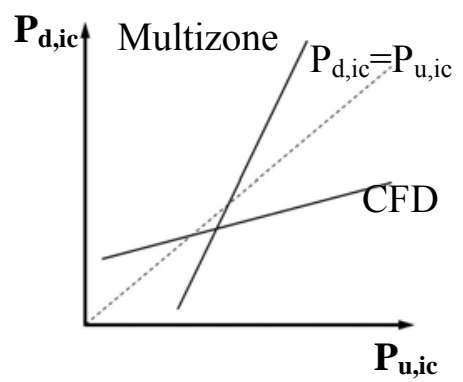

(a) Analysis of solution existence

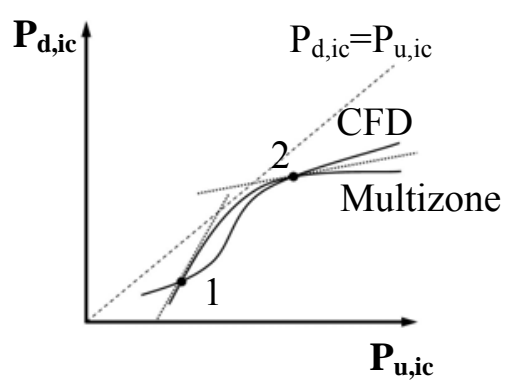

(b) Scenario of two solutions

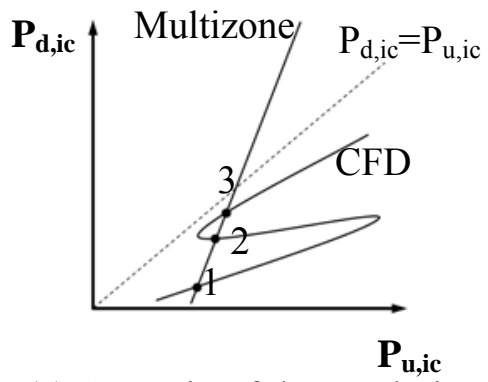

(c) Scenario of three solutions

Figure 2 Solution existence and uniqueness analysis of the curves of $\mathrm{P}_{\mathrm{d}, \mathrm{ic}}-\mathrm{P}_{\mathrm{u}, \mathrm{ic}}$

The method of reduction to absurdity is used to investigate the uniqueness of the coupling solution. For the $\mathrm{P}_{\mathrm{d} \text {,ic }}-\mathrm{P}_{\mathrm{u}, \mathrm{ic}}$ relations, Figures $2 \mathrm{~b}$ and $2 \mathrm{c}$ show two possible scenarios of multiple solutions. Suppose we already find a solution at Point 1 through the above analysis of solution existence, we then assume that the $\mathrm{P}_{\mathrm{d} \text {,ic }}-\mathrm{P}_{\mathrm{u}, \mathrm{ic}}$ curves may intersect at other points. In the first scenario as indicated by Point 2 in Figure 2b, the slope of CFD curve at Point 2 is less than unity, which satisfies Eq. (26). The slope of multizone curve at Point 2, however, does not satisfy Eq. (27) so the first scenario is impossible and Point 2 cannot be a coupled solution. The second scenario shown in Figure $2 \mathrm{c}$ is also impossible because one specific pressure boundary condition $\mathrm{P}_{\mathrm{u}, \mathrm{ic}}$ in CFD can have only one corresponding $\mathrm{P}_{\mathrm{d} \text {,ic }}$ for a given situation (including given numerical models and techniques). Therefore, Points 2 and 3 cannot be coupled solutions and Point 1 is the only solution to multizone and CFD coupling. Please note that this conclusion is based on the assumption that both the CFD and multizone methods can have a unique solution.

The analysis here only discusses the situation, in which the airflow of Path ic is from Zone $\mathrm{i}$ to Zone $\mathrm{c}$ as in Figure 1. It is easy to apply a similar analysis to prove solution existence and uniqueness when the airflow of path ic is from Zone c to Zone i. In conclusion, there is thus one and only one solution for a multizone and CFD coupling. The question now is how to obtain this unique solution. 


\section{Different coupling methods}

The unique solution of airflow coupling can only be obtained by applying appropriate coupling methods, which determine how the boundary conditions are exchanged between multizone and CFD models. Negrao (1995) claimed that the pressure boundary condition was applicable to the cases where the inlet momentum changes the flow locally but does not affect substantially the airflow pattern of CFD zone. The velocity boundary condition should be used for inlet openings where the momentum magnitude can significantly modify the zone air flow pattern and must be known in advance. Unfortunately, we could not find the details.

This paper investigats the coupling methods by studying the basic governing equations of the airflow coupling. As shown in Figure 1, when the airflow of Path ic is from Zone i to Zone c, the upwind total pressure, $\mathrm{P}_{\mathrm{u}, \mathrm{ic}}$, the downwind total pressure, $\mathrm{P}_{\mathrm{d}, \mathrm{ic}}$, and the airflow rate, $\mathrm{F}_{\mathrm{ic}}$, are the boundary conditions to be exchanged between the two programs. Three coupling methods are possible according to permutation and combination:

1. Multizone gives $\mathrm{P}_{\mathrm{u}, \mathrm{ic}}$ to CFD and CFD returns $\mathrm{P}_{\mathrm{d}, \mathrm{ic}}$ to multizone;

2. Multizone gives $P_{u, i c}$ to $C F D$ and CFD returns $F_{i c}$ to multizone; and

3. Multizone gives $F_{\text {ic }}$ to $C F D$ and CFD returns $P_{d, \text { ic }}$ to multizone.

We found that the above three coupling methods will result in different assembled matrix equations. When pressure and airflow rate boundary conditions are used together, such as in Methods 2 and 3, the assembled matrix equation is in the form of Eq. (10). Howerver, when only pressure bounary conditions are employed (Method 1), Eq. (10) becomes

$\mathbf{C}_{1} \mathbf{P}=\mathbf{B}_{1}$

Different assembled matrix equations will not have the same numerical characteristics. The numerical performance of one matrix equation could be better than others.

Selection of the best coupling approach by the Scarborough criterion

Scarborough (1966) established a convergent criterion for a Gauss-Seidel solution for a set of linear equations. The criterion is often used to evaluate CFD equations. In this study, multizone and CFD programs provide complementary boundary conditions and the coupled program basically tries to obtain a Gauss-Seidel solution of the assembled matrix equation. Thus the Scarborough criterion could be used.

For the Gauss-Seidel solution of a linear system like Eq. (29), a sufficient convergence condition, the Scarborough criterion, is to satisfy Ineqality (30):

$$
\begin{aligned}
& \mathrm{a}_{\phi, \mathrm{P}} \phi_{\mathrm{P}}=\sum \mathrm{a}_{\phi, \mathrm{nb}} \phi_{\mathrm{nb}}+\mathrm{b}_{\phi} \\
& \frac{\sum\left|\mathrm{a}_{\phi, \mathrm{nb}}\right|}{\left|\mathrm{a}_{\phi, \mathrm{P}}\right|}\left\{\begin{array}{l}
\leq 1 \\
<1
\end{array}\right.
\end{aligned}
$$

for at least one equation (30b)

The Scarborough criterion concludes that Eq. (29) has a convergent solution if the matrix is 'diagonally dominant'. 
In a coupled simulation, Inequality (30b) can always be satisfied so long as at least one zone connects directly to another with a constant pressure in Eq. (10) or (28). The multizone calculation itself actually requires that at least one zone with unknown pressure be connected to another with a constant pressure. Otherwise, the airflow system in a multizone program will be singular and can have no unique solutions (Lorenzetti, 2002). The zone with constant pressure can be the ambient with zero pressure or a zone with constant pressure specified. Inequality (30b) is therefore satisfied automatically in a coupled simulation.

Among the three methods, only Method 1 satisfies Inequality (30a) since it solves Eq. (28), which is a combination of Eqs. (5) and (8) and where each independent off-diagonal pressure will introduce its coefficient to that of the diagonal pressure of the matrix. Methods 2 and 3 solve the matrixes in the form of Eq. (10) and $\mathbf{F}$ is an independent vector. The coefficients of $\mathbf{F}$ do not contribute to those of the diagonal pressure in the matrix. The condition of 'diagonal dominance' may not always be satisfied for Eq. (10). Method 1 therefore is the only one that satisfies the Scarborough criterion and is guaranteed to have a convergent solution.

Since the Scarborough criterion is only a sufficient condition and the other two methods may still produce a convergent solution, it may be not convincing enough to conclude that Method 1 is the best method. A stability analysis should be performed to provide an in-depth investigation of the numerical performance of the coupling methods.

Numerical stability analysis

In order to further investigate the stability of the three coupling methods, we have further examined the iterative procedure when exchanging boundary conditions between the multizone and CFD programs in a coupled simulation. Figure 3 shows that, during a coupled solving procedure, the output of one program becomes the input of the other. When both inputs and outputs stabilize (their values do not change), the solution of the coupling is considered convergent. This iterative coupling procedure can be regarded as a closed-loop system. If $r$ is the input parameter of a multizone program from CFD and $r_{k}$ is its value at the coupling iteration $\mathrm{k}$, we can define the difference of $r$ at this iteration as $\Delta r_{k}=\left|r_{k+1}-r_{k}\right|$.

Figure 3 illustrates that the system equation for a multizone program is $M$, and its solution at iteration $\mathrm{k}, \mathrm{i}_{\mathrm{k}}$, can be calculate as $\mathrm{i}_{\mathrm{k}}=M\left\{\mathrm{r}_{\mathrm{k}}\right\}$. Similarly, we have $\mathrm{r}_{\mathrm{k}+1}=C\left\{\mathrm{i}_{\mathrm{k}}\right\}$ for the CFD program.

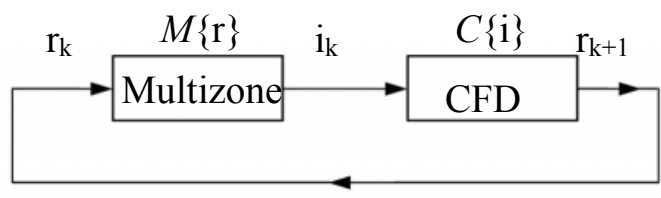

Figure 3. Schematic of the coupling procedure at the coupling iteration $\mathrm{k}$

If $\Delta \mathrm{r}_{\mathrm{k}}$ can be expressed by the partial derivatives of $M\{\mathrm{r}\}$ and $C\{\mathrm{i}\}$, we have

$\Delta \mathrm{r}_{\mathrm{k}}=\left|\frac{\partial M}{\partial \mathrm{r}} \times \frac{\partial C}{\partial \mathrm{i}}\right| \times \Delta \mathrm{r}_{\mathrm{k}-1}=\left|\frac{\partial M}{\partial \mathrm{r}} \times \frac{\partial C}{\partial \mathrm{i}}\right|^{\mathrm{k}} \times \Delta \mathrm{r}_{0}$

Then when $\mathrm{k}$ is sufficiently large, the coupled simulation will be stable and convergent only if 
$\left|\frac{\partial M}{\partial \mathrm{r}} \times \frac{\partial C}{\partial \mathrm{i}}\right| \leq 1$

Here, we call the term of $\left|\frac{\partial \boldsymbol{M}}{\partial \mathbf{r}} \times \frac{\partial \boldsymbol{C}}{\partial \mathbf{i}}\right|$ as the Fluctuation Term (hereafter the FT). The derivatives of $M\{r\}$ and $C\{\mathrm{i}\}$ are shown in Eqs. (16) and (17). Table 1 compares the FTs among the three coupling methods. The last column provides the stability criteria for a coupled solution.

Table 1 . Stability conditions for the three coupling methods

\begin{tabular}{|c|c|c|c|c|}
\hline & $\mathbf{i}$ & $\mathbf{r}$ & $\left|\frac{\partial \boldsymbol{M}}{\partial \mathbf{r}} \times \frac{\partial \boldsymbol{C}}{\partial \mathbf{i}}\right|$ & STABILITY CRITERIA \\
\hline $\begin{array}{c}\text { Method } \\
\mathbf{1}\end{array}$ & $\mathrm{P}_{\mathrm{u}, \mathrm{ic}}$ & $\mathrm{P}_{\mathrm{d}, \mathrm{ic}}$ & {$\left[\frac{\mathrm{C}_{\mathrm{L}, \mathrm{ic}}}{\mathrm{C}_{\mathrm{L}, \mathrm{ic}}+\mathrm{C}_{\mathrm{L}, \mathrm{ij}}} \times \frac{\mathrm{C}_{\mathrm{L}, \mathrm{P}}}{\mathrm{a}_{\mathrm{P}}+\mathrm{C}_{\mathrm{L}, \mathrm{P}}}, 1\right)$} & $\begin{array}{l}\text { unconditionally stable for } \\
\text { all } \mathrm{C}_{\mathrm{L}, \mathrm{ic}}, \mathrm{C}_{\mathrm{L}, \mathrm{ij}}, \mathrm{C}_{\mathrm{L}, \mathrm{P}}, \text { and } \mathrm{a}_{\mathrm{P}}\end{array}$ \\
\hline $\begin{array}{c}\text { Method } \\
\mathbf{2}\end{array}$ & $\mathrm{P}_{\mathrm{u}, \mathrm{ic}}$ & $\mathrm{F}_{\mathrm{ic}}$ & $\left(0, \frac{\mathrm{a}_{\mathrm{P}} \mathrm{C}_{\mathrm{L}, \mathrm{ic}}}{\mathrm{C}_{\mathrm{L}, \mathrm{ij}}\left(\mathrm{a}_{\mathrm{P}}+\mathrm{C}_{\mathrm{L}, \mathrm{P}}\right)}\right]$ & $\frac{\mathrm{C}_{\mathrm{L}, \mathrm{ij}}}{\mathrm{C}_{\mathrm{L}, \mathrm{ic}}}\left(1+\frac{\mathrm{C}_{\mathrm{L}, \mathrm{P}}}{\mathrm{a}_{\mathrm{P}}}\right)=\left\{\begin{array}{l}<1, \text { conditionally } \\
\geq 1,\end{array}\right.$ \\
\hline $\begin{array}{c}\text { Method stable } \\
\mathbf{3}\end{array}$ & $\mathrm{F}_{\mathrm{ic}}$ & $\mathrm{P}_{\mathrm{d}, \mathrm{ic}}$ & $\left(0, \frac{\mathrm{C}_{\mathrm{L}, \mathrm{ij}} \mathrm{C}_{\mathrm{L}, \mathrm{P}}}{\mathrm{a}_{\mathrm{P}}\left(\mathrm{C}_{\mathrm{L}, \mathrm{ij}}+\mathrm{C}_{\mathrm{L}, \mathrm{ic}}\right)}\right.$ & $\frac{\mathrm{a}_{\mathrm{P}}}{\mathrm{C}_{\mathrm{L}, \mathrm{P}}}\left(1+\frac{\mathrm{C}_{\mathrm{L}, \mathrm{ic}}}{\mathrm{C}_{\mathrm{L}, \mathrm{ij}}}\right)=\left\{\begin{array}{l}<1, \\
\geq 1,\end{array}\right.$ \\
\hline
\end{tabular}

The stability criterion for Method 1 is satisfied unconditionally, because $C_{L, i c}, C_{L, i j}, C_{L, P}$ and $\mathrm{a}_{\mathrm{P}}$ are all positive and the derivatives of $M\{\mathrm{r}\}$ and $C\{\mathrm{i}\}$ are always less than one. Together with the convergence analysis, one can conclude that Method 1 can lead to convergent and stable solutions. In addition, it is also indicated that the greater $\mathrm{C}_{\mathrm{L}, \mathrm{ij}}$ and $\mathrm{a}_{\mathrm{P}}$ are, the faster the coupled program reaches a convergent solution.

The criteria for Methods 2 and 3 shows that the two methods are conditionally stable. With Method 2, the greater $\mathrm{C}_{\mathrm{L}, \mathrm{j}}$ and the smaller $\mathrm{C}_{\mathrm{L}, \mathrm{ic}}$ are, the more stable the coupling. However, Method 3 requires a smaller $C_{L, j i j}$ to reach a better stability in the coupled solution. Thus, Method 1 seems the best. This can be further proved by numerical experiments.

\section{Numerical Experiment}

Numerical experiments of the solution characteristics for the three coupling methods was conducted by coupling CONTAM (Walton and Dols, 2003), a multizone program, with CFD0, a three-dimensional CFD code. The CFD0 is based on the version developed by Srebric et. al (1999) through conversion of FORTRAN to C. The conversion makes the coupling much easier because CONTAM is written in C. CFD0 utilizes SIMPLE algorithm 
and the solver of line-by-line TDMA (Patankar, 1980). Turbulence is accounted for by Zero-equation eddy-viscosity model (Chen and Xu, 1998).

The numerical experiment is designed with the following considerations:

- The assumptions of multizone models is inappropriate for at least one zone so that the airflow coupling with CFD program for the zone is necessary;

- The numerical experiments should be able to illustrate that how non-uniform distributions of airflow variables, especially pressures, and airflow patterns affect building airflow distributions;

- The numerical experiments should be as simple as possible so that it is easy to apply the theoretical analysis.

Based on these considerations, this paper investigates two types of flows: pressure gradient flows in an office suite and cross ventilation in a four-zone building model. In both cases, multizone network models cannot provide reasonable predictions of air distributions and therefore the coupled program is employed to improve the calculations.

Pressure gradient flows in an office suite

The first case concerns isothermal pressure gradient flows at steady state in an office suite with four offices and a long hallway as shown in Figure 4. For simplicity, this paper simplified the office suite into two-dimensional one in X-Y plane.

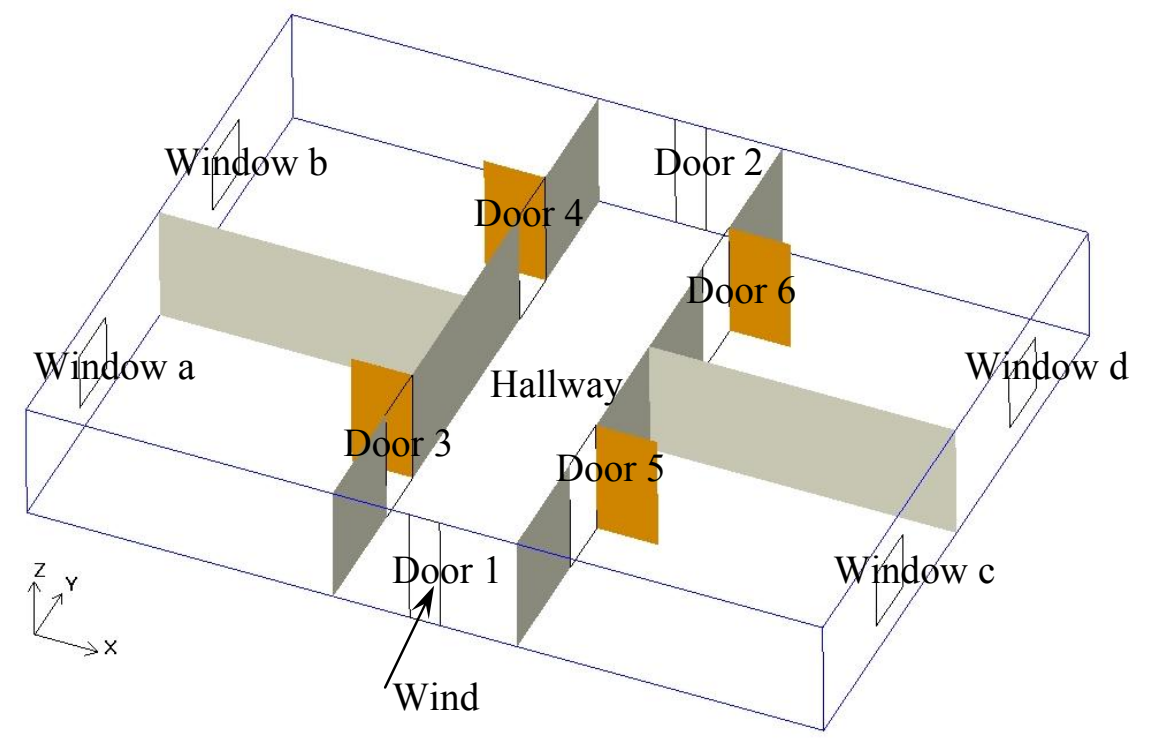

Figure 4 The layout of an office suite with four offices and one hallway

The hallway, $3 \mathrm{~m}(\mathrm{X}) \times 10 \mathrm{~m}(\mathrm{Y})$, was selected as the CFD zone. The open area of Doors 1 and 2 was $0.5 \mathrm{~m}^{2}$ each, and that of Doors 3 through 6 was $1 \mathrm{~m}^{2}$ each. When Windows a, b, c and d were closed, the crack area is estimated to be $0.0002 \mathrm{~m}^{2}$ each. Other possible leakages in the office suite, e.g. cracks at wall joints, are neglected in current simulation. When they were opened, the cross sectional area was $1 \mathrm{~m}^{2}$ each. Since the flow was assumed isothermal so the pressure difference due to density difference was zero for every flow path and wind pressure 
was the only driving force. At Door 1 , the wind pressure was assumed constant at $1 \mathrm{~Pa}$ and those of other doors were $0 \mathrm{~Pa}$. This investigation studied two scenarios:

- Scenario A: Windows a, b, c and d were closed so that the airflow rates and thus pressure drops through Doors 3, 4, 5 and 6 were close to zero;

- Scenario B: Windows a, b, c and d were open so that the airflow rates and thus pressure drops of Doors 3, 4, 5 and 6 were none-zero.

For the two-dimensional CFD calculations, the convergence criterion is that the normalized residuals are less than 0.01 for all the variables solved and the grid of $21 \times 42(\mathrm{X} \times \mathrm{Y})$ is used for the hallway. For multizone calculations, the non-linear equation solver of simple trust region is used and the flow model of orifice equation is applied to all flow paths of multizone method. The total computing time of the coupled simulation of method 1 is $125 \mathrm{~s}$ for Scenario $\mathrm{A}$ and $53 \mathrm{~s}$ for Scenario B on a Pentium $42.0 \mathrm{GHz}$ PC. The total computing time can be divided into three parts: multizone calls (multizone internal iterations), the iterative exchange of boundary conditions between multizone and CFD (external iterations), and CFD calls (CFD internal iterations). CFD internal iterations take most of the total computing time. At the early stage of the coupled simulation, each CFD call needs more than 1000 internal iterations to obtain an intermittent converged CFD solution. At the later stage, when the coupled simulation tends to converge, one internal iteration of CFD is sufficient for CFD convergence. Therefore, the exchange of boundary conditions between multizone and CFD programs gets more frequent when the coupled simulation is closer to the coupling convergence.

Figure 5 shows the changes of airflow rates with coupling iterations by the three coupling methods in these two scenarios. Figures $5 \mathrm{a}$ is for Door 1 in Scenario A and Figure $5 \mathrm{~b}$ is for Door 3 in Scenario B. Figure 5a shows that with Methods 1 and 3, the coupled simulation converges after about 15 iterations. This means that the exchange of boundary conditions between multizone and CFD programs undergoes 15 times before the coupling convergence as evaluated by Eq. (11). The calculated airflow rates were $0.367 \mathrm{~kg} / \mathrm{s}$ with Method 1 and $0.372 \mathrm{~kg} / \mathrm{s}$ with Method 3. The two numbers are close so they support the theory of the solution uniqueness. The small difference may be due to their different ways to apply boundary conditions in CFD calculations. In Method 1, a uniform boundary pressure was employed while Method 3 assumes a uniform distribution of velocity for each path. Method 2 diverged after the first several iterations in Scenario A even if very high under-relaxations were used. The calculated airflow rates by Method 2 were too unrealistic so the results of Method 2 were not plotted in Figure 5. On the other hand, since Door 1 is connected to the ambient with a known pressure, its airflow rate can be calculated directly from local pressures from CFD calculation at each coupling iteration. Therefore, for Method 3, only the convergence history of CFD0 (Method-3-CFD0) is shown, because it is the same as that of Method-3-CONTAM.

Compared with Scenario A, the three coupling methods behaved differently for Scenario B as shown in Figure 5b, which shows the flow rates through Door 3 during coupling. For Scenario B, Methods 1 and 2 could give a convergent solution and calculated the same flow rate through Door 3. Method 3 diverged quickly and failed to produce reasonable airflow rates during the iteration. 


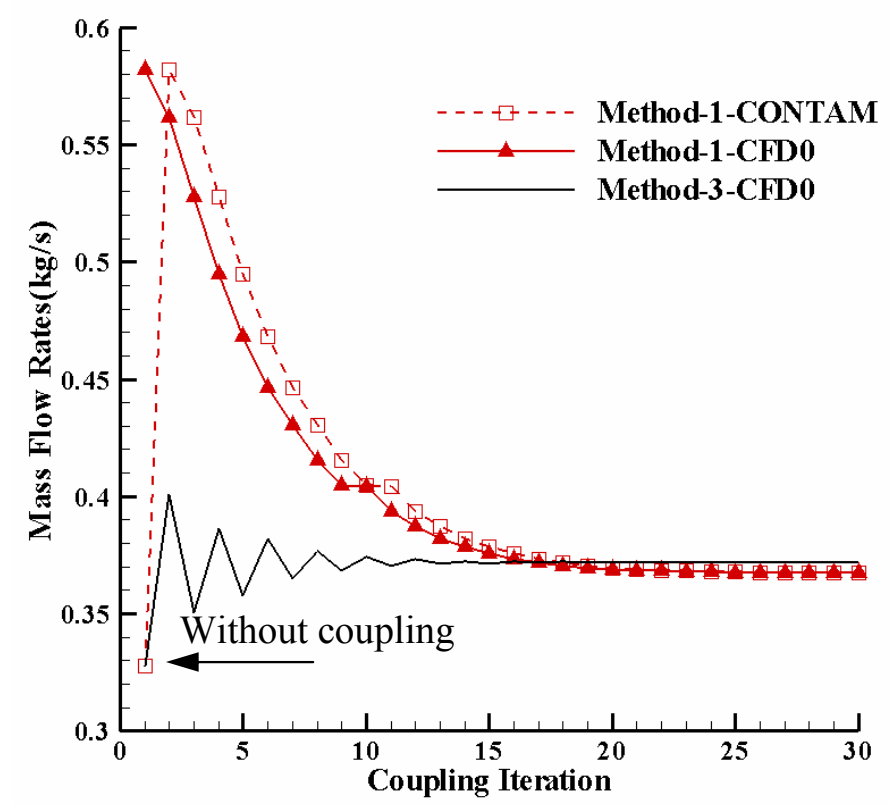

(a)

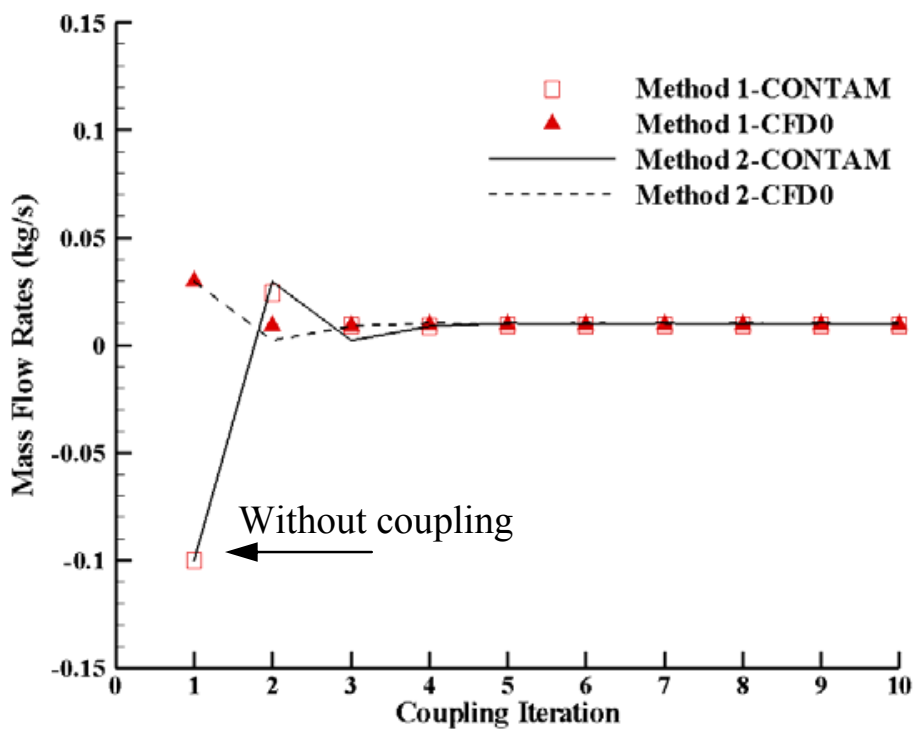

(b)

Figure 5. Airflow rates calculated with different coupling methods (a) airflow rate through Door 1 in Scenario A by Methods 1 and 3; (b) airflow rate through Door 3 in Scenario B by Methods 1 and 2

The distinct numerical performances of the three coupling methods can be explained by studying their stability performance based on the stability criteria in Table 1 . By calculating the coefficients, $C_{L, i c}, C_{L, P}, C_{L, i j}$ and $a_{P}$, for Scenarios $A$ and $B$, one can obtain the FTs, $\left|\frac{\partial \boldsymbol{M}}{\partial \mathbf{r}} \times \frac{\partial \boldsymbol{C}}{\partial \mathbf{i}}\right|$, for all coupling methods as shown in Table 2 . The stability criteria require that the FTs must be smaller than 1.0 so Method 1 is unconditionally stable for Scenarios A and B. Furthermore, the smaller the FT is, the faster the coupled simulation reaches convergence. This can be easily seen from Figure 5 in which it took Method 1 four iterations in Scenario B to reach convergence while 15 iterations in Scenario A. Furthermore, Table 2 illustrates that the FTs of 
Method 2 in Scenario B and Method 3 in Scenario A were much smaller than 1.0, which guarantee converged solutions. The instabilities of Method 2 in Scenario A and Method 3 in Scenario B can also be explained by their high FTs shown in Table 2. The FT can be greater than 1.0 during coupling iterations that leads finally to divergences.

Table 2. The fluctuation terms (FTs) of different coupling methods for Scenarios A and B for the pressure gradient flows in an office suite

\begin{tabular}{|c|c|c|}
\hline & \multicolumn{2}{|c|}{$\left|\frac{\partial \boldsymbol{M}}{\partial \mathbf{r}} \times \frac{\partial \boldsymbol{C}}{\partial \mathbf{i}}\right|$} \\
\hline & Scenario A & Scenario B \\
\hline Method 1 & {$[0.5,1)$} & {$[0.002,1)$} \\
\hline Method 2 & $(0,1879.7]$ & $(0,0.003]$ \\
\hline Method 3 & $(0,0.002]$ & $(0,41.5]$ \\
\hline
\end{tabular}

Figure 5 also compares the calculated airflow rates with and without coupling (the results at the end of the iterations versus those at Iteration 1). If a positive value means an inflow for the hallway, the relative differences can be $11 \%$ for Door 1 in Scenario A. Figure 6 gives more detailed comparisons. For Scenario A as shown in Figure 6A, since Windows a, b, c and d were closed, the flow rates of Doors 3 through 6 were close to zero after coupling. The largest difference before and after coupling is around 30\%. When Windows a, b, c and d were open in Scenario B, the flow directions through Doors 3 and 5 even change from outflows to inflows after coupling as shown in Figure $6 \mathrm{~b}$. As a result, the airflow rates of other doors change dramatically in Scenario B.

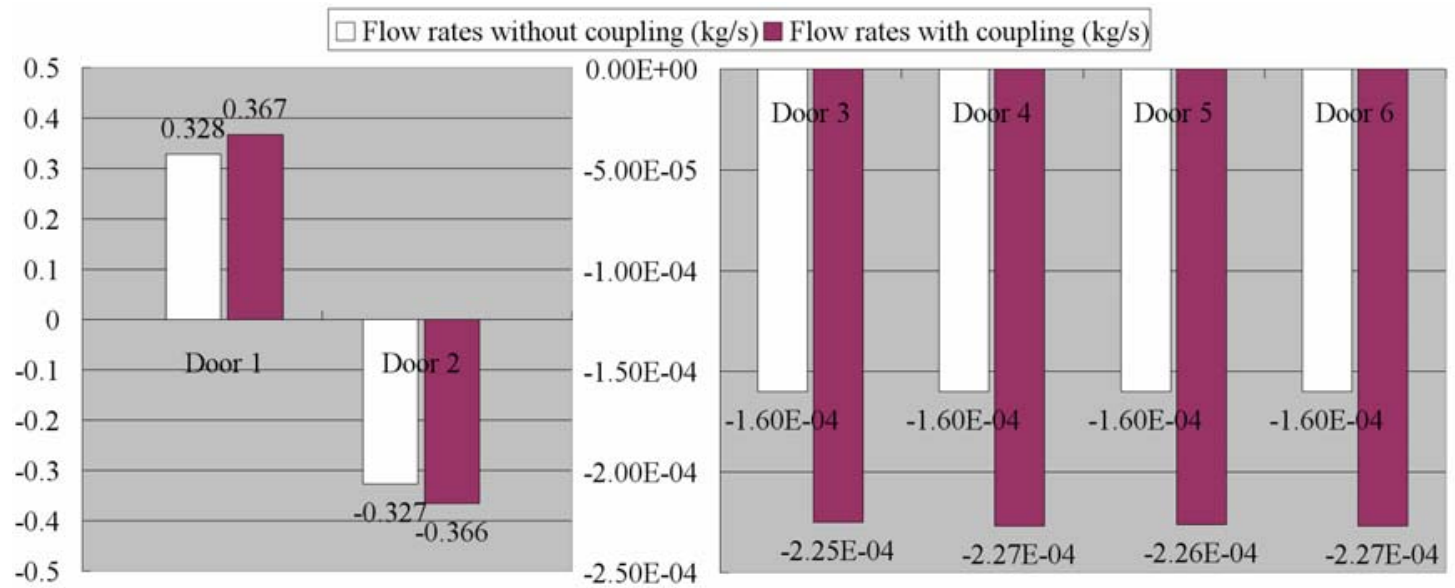

(a) 


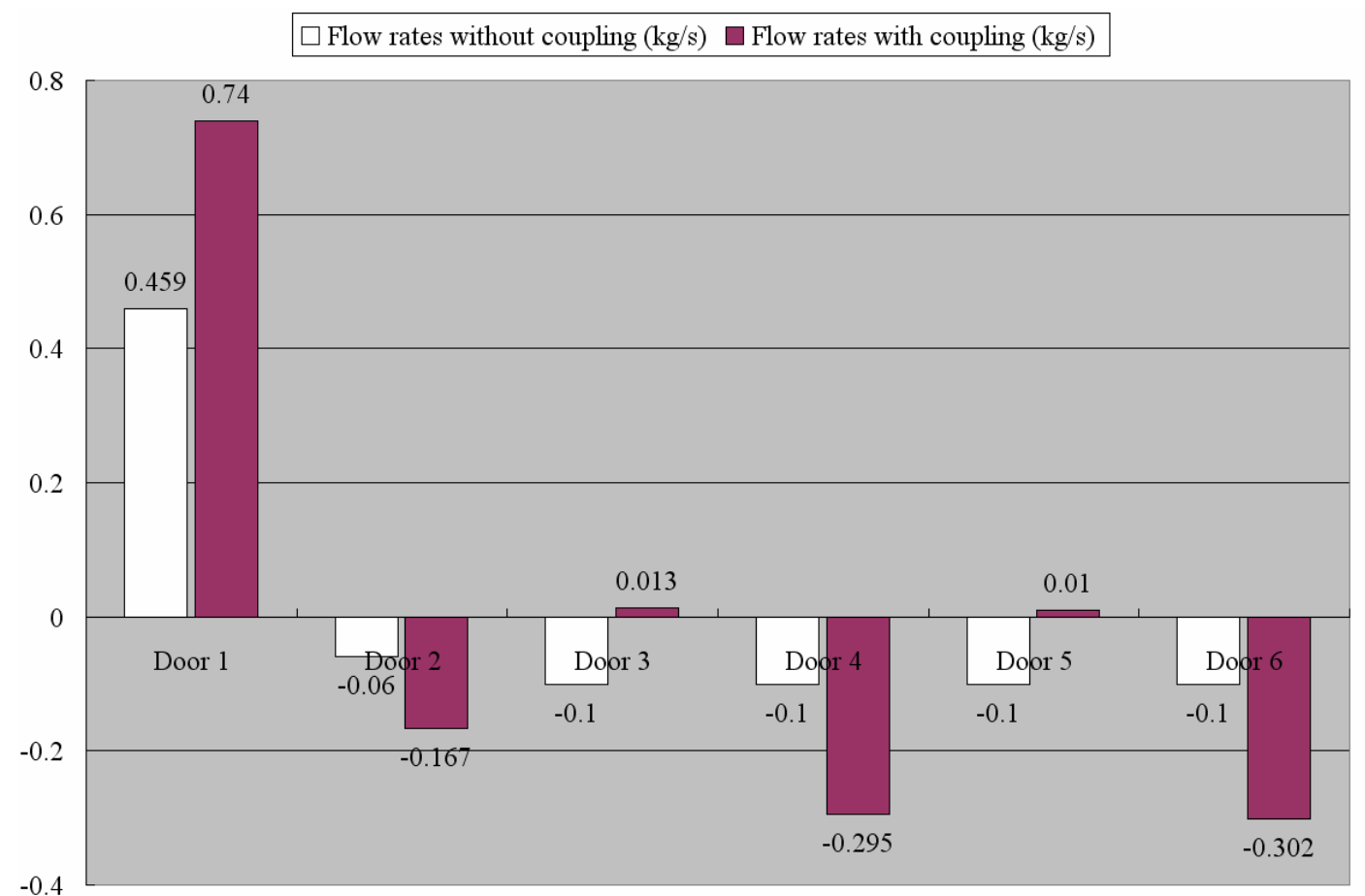

(b)

Figure 6. Comparisons of calculated airflow rates through different openings in an office suite with and without coupling (a) Scenario A and (b) Scenario B.

The dramatic changes of airflow rates after coupling in Scenario B provide a clear evidence that, when the homogeneous assumption of multizone models are inappropriate, the airflow pattern play an important role in building air distributions. Figure 7 shows the airflow patterns in the hallway calculated by CFD. For Scenario A shown in Figure 7a, a recirculation area formed at each side of Door 1 whereas, it is not big enough to affect Doors 3 and 5 . Moreover, the local pressures at Doors 3 through 6 were almost the same so that the calculated airflow rates were close to each other.

However, when Windows a, b, c and d are open in Scenario B, Figure $7 b$ shows that the airflow pattern changed dramatically. Compared with Scenario A, the airflow through Door 1 has less flow resistances and the flow momentum is preserved after entering the hallway. The recirculation areas therefore extended far enough to affect the local flow near Doors 3 and 5. Instead of outflows calculated by CONTAM, air was induced through Doors 3 and 5 into the hallway. Figure $7 \mathrm{~b}$ also illustrates that the pressure distribution in Scenario B is highly non-uniform, which explains why the airflow rates of Door 4 and 6 change more after coupling than those in Scenario A. 


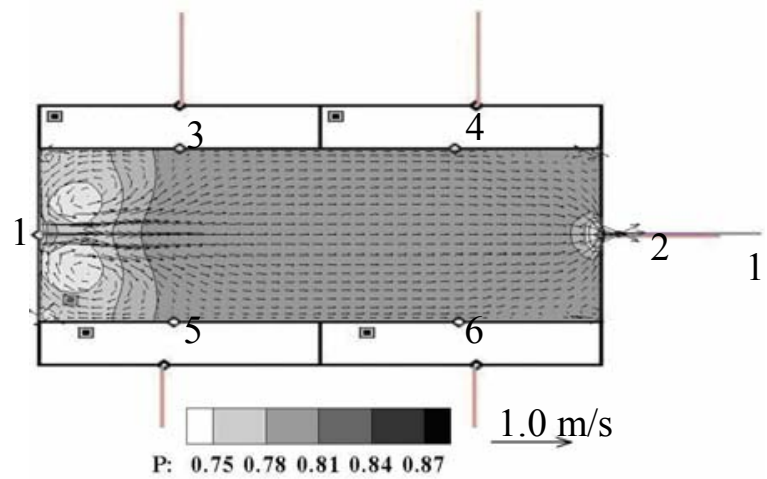

(a)

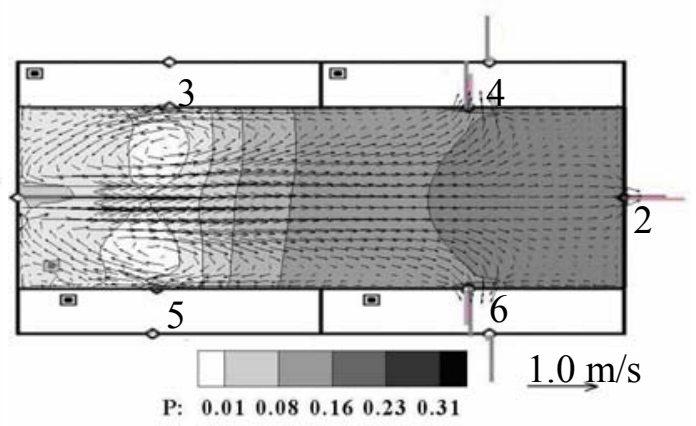

(b)

Figure 7. Airflow patterns and pressure distributions after coupling in the office suite (a) Scenario A with closed windows a, b, c and d; (b) Scenario B with open windows a, b, c and d

Figures 6 and 7 shows that CFD solutions were a little asymmetrical, e.g. for Door 3 and Door 5 in Figure 6b, the flow rates were 0.013 and 0.01 respectively. One explanation is that CFD convergence criterion in this case was that CFD residual was less than $1 \%$. The residual of CFD simulation can be roughly calculated as $[(0.302-0.295)+(0.013-0.01)] /(0.763) \sim 0.01$ ( 0.763 is the total inflow rate). So the small difference of flow rates was caused by simulation residuals. On the other hand, perfect symmetry normally is not easy to be achieved in CFD simulations (Chen and Jiang, 1992).

The numerical experiment for the pressure gradient flows in the office suite demonstrates that the coupling solution exists and is unique. Method 1 is indeed the best coupling method. Furthermore, the coupled program can improve the accuracy of the multizone models by considering the airflow patterns and non-uniform pressures inside CFD zones.

Cross ventilation in a four-zone building model

For simplicity, the numerical experiment for the office suite was conducted two-dimensionally. Negrao (1995) found that airflow coupling of multizone and CFD models may not work for three-dimensional cases. In order to further test the coupled program, a more complex three-dimensional problem, cross ventilation in a four-zone building model, was studied.

Sawachi et al. (2003) used a full-scale building model in a wind tunnel to measure discharge coefficients at the building openings under different wind directions. Figure $8 \mathrm{a}$ shows the wind tunnel sketch. The test model placed in the wind tunnel was a full-scale building model that was $5.53 \mathrm{~m}(\mathrm{X}) \times 5.53 \mathrm{~m}(\mathrm{Y}) \times 3.0 \mathrm{~m}(\mathrm{Z})$, and was divided into four sub-zones with the same size. The full-scale building model can be turned around to study the impact of different wind directions. This paper only used the case where the wind was perpendicular to the opening in the building model. Figure $8 \mathrm{~b}$ illustrates the three-dimensional view of the 4-zone building model. With a strong momentum, the wind flows into Zone F through Path A, the size of which is $0.86 \mathrm{~m}(\mathrm{~W}) \times 1.74 \mathrm{~m}(\mathrm{H})$, and distributes among other three sub-zones through internal Paths B and C, the size of which is $1.68 \mathrm{~m}(\mathrm{~W}) \times 2.5 \mathrm{~m}(\mathrm{H})$ each. Zone $\mathrm{F}$ is therefore subject to the momentum effect of the incoming wind and the coupled simulation selected Zone $\mathrm{F}$ as the CFD zone. 

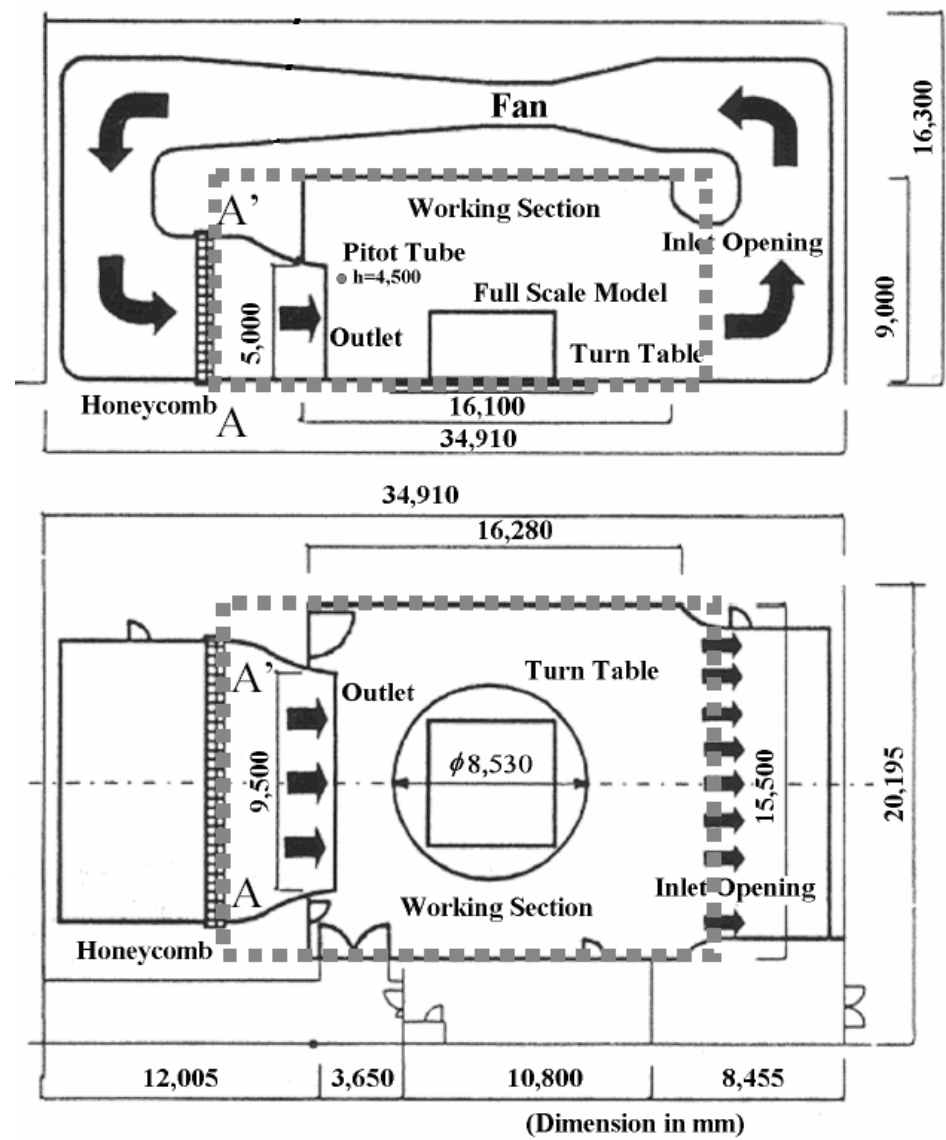

(a)

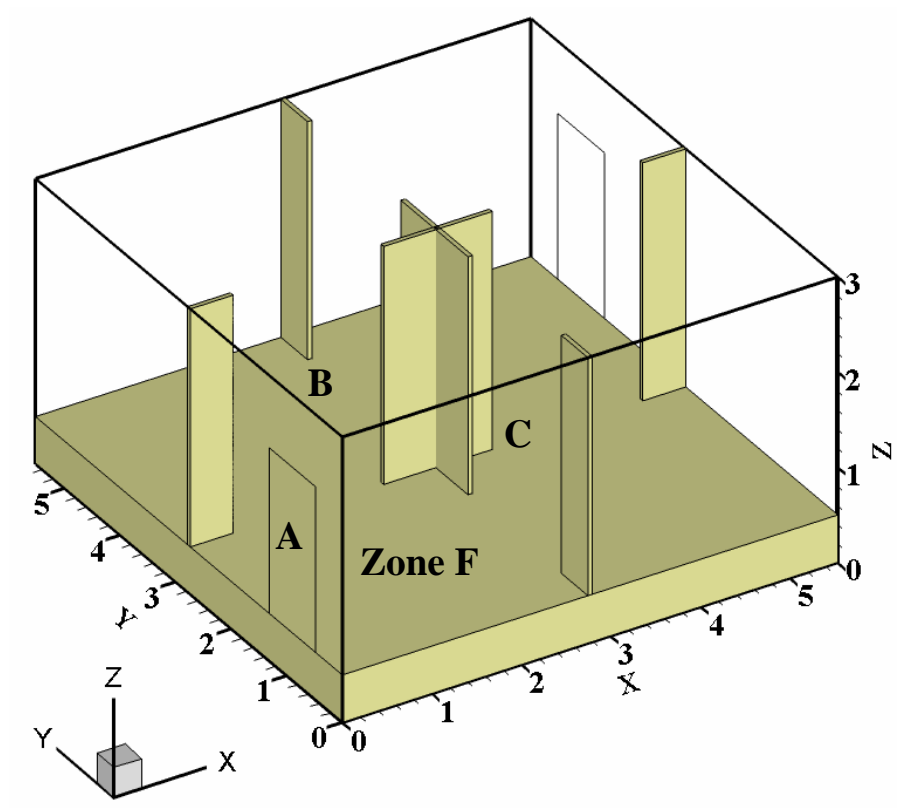

(b)

Figure 8 The 4-zone building model (a) section (top) and plane (bottom) of the wind tunnel laboratory (Sawashi et al. 2003); (b) the three-dimension view of the building model 
The same convergence criterion as the previous case is used for the three-dimensional CFD runs and the grid of this case is $19 \times 19 \times 24(\mathrm{X} \times \mathrm{Y} \times \mathrm{Z})$. The total computing time of the coupled simulation of Method 1 is $184 \mathrm{~s}$ on a Pentium $42.0 \mathrm{GHz}$ PC, which is more than that of the previous case because of the increased grid numbers in CFD simulation.

Figure 9a illustrates the experimental airflow pattern for the building model. It shows that, due to the preserved momentum of the incoming wind, the air in Zone F mostly flowed from opening A through Path C. Opening B has little flow. Obviously, the momentum effect was very significant for this case. Figure $9 \mathrm{~b}$ shows the calculated airflow pattern after the coupling by Method 1, which is similar to that from the experiment except that the calculated recirculation area is smaller. The difference is mainly caused by specifying the uniform distribution of velocities in Opening A that is not uniform in the experiment. On the other hand, since the coupled simulation applied the CFD simulation only to Zone F, its prediction is a combination of the results of multizone and CFD simulations. Therefore, the calculated airflow pattern may be different from the experiment.

Although the coupled simulation may not be as accurate as the application of CFD to all zones, it is still able to provide more reasonable airflow predictions than that by multizone model alone. When the flow rate through Path $\mathrm{A}$ is $2.386 \mathrm{~kg} / \mathrm{s}$, CONTAM alone would calculate the same flow rate for Paths B and C at $1.193 \mathrm{~kg} / \mathrm{s}$ due to neglecting the preserved momentum inside Zone F. However, the coupled program calculates the flow rate of $0.746 \mathrm{~kg} / \mathrm{s}$ for Path B and $1.640 \mathrm{~kg} / \mathrm{s}$ for Path C. The difference is around $60 \%$ between the solutions by CONTAM alone and by the coupled program. This is because the strong momentum at Path A can be captured by the coupled program when applying CFD for Zone F.

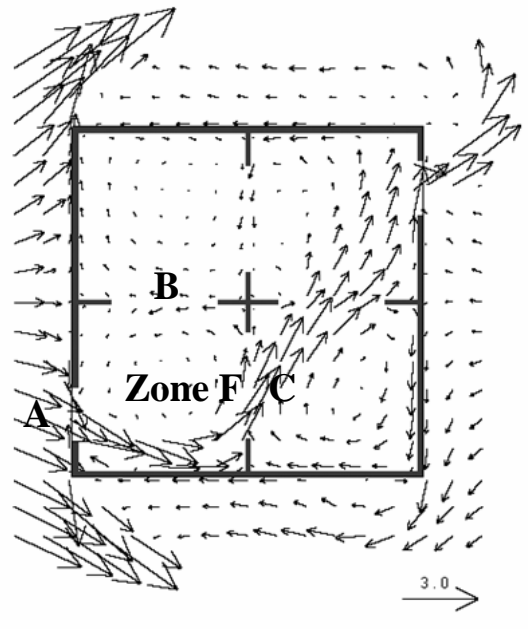

(a)

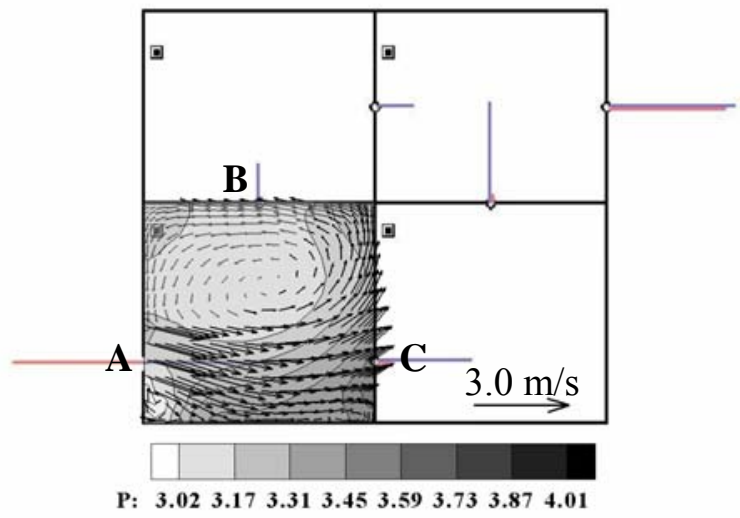

(b)

Figure 9 The coupled simulation in a four-zone house model with cross ventilation (a) the measured velocity field of the four-zone house model; (b) the velocity and pressure fields by the coupled simulations.

The above analysis uses the results obtained by Method 1 before and after coupling. By using Methods 2 and 3, we can also achieve converged solutions for this case. Figure 10 shows the airflow rates of Path $\mathrm{B}$ during the coupled solution with the three methods. All the three methods have led to the same flow rate at Path B, which again supports the theory of unique solution. Compared with Method 1, the coupling by Methods 2 and 3, however, fluctuate 
during iterations as shown in the figure. This further proves conditional stabilities of the two methods. Due to the nonlinearity of the problem, the linear flow coefficients, $\mathrm{C}_{\mathrm{L}, \mathrm{ij}}$ and $\mathrm{C}_{\mathrm{L}, \mathrm{ic}}$, can change during the iterative coupling. Although the overall trend of the coupling is convergent, the stability criteria in Table 1 may not always be satisfied at some iterations, which as a result cause the fluctuations.

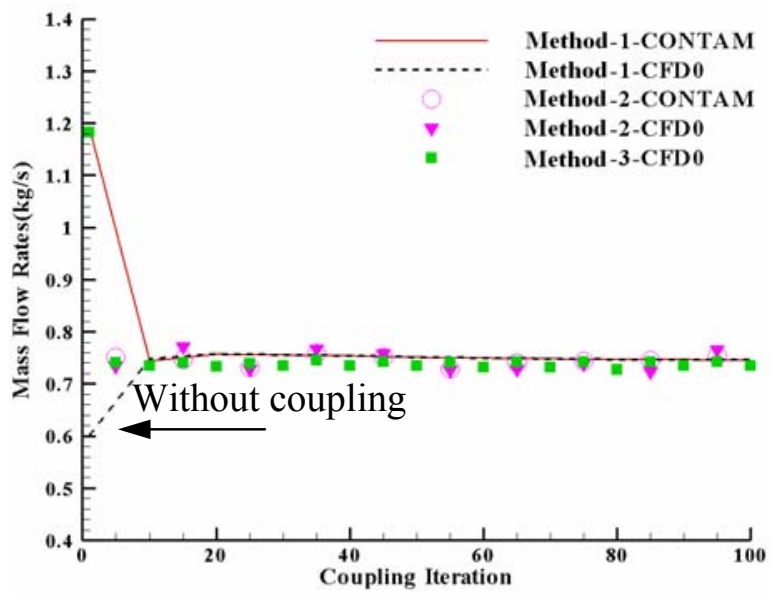

Figure 10 Airflow rate through Path B during the iteration with the three coupling methods in a four-zone building model with cross ventilation

This investigation is for large openings, where CFD plays an important role and can improve the results. If cracks become very important, multizone model alone can handle it, where no coupling between CFD and multizone is required. This study does not suggest the coupling of CFD and multizone for crack type of problems.

\section{Conclusions}

This investigation studied three methods to improve the accuracy of airflow calculations in a multizone network model by coupling it with a CFD program (Figure 1):

1. Multizone gives $P_{u, i c}$ to CFD and CFD returns $P_{d, i c}$ to multizone;

2. Multizone gives $P_{u, i c}$ to $C F D$ and CFD returns $F_{i c}$ to multizone; and

3. Multizone gives $F_{\text {ic }}$ to $C F D$ and $C F D$ returns $P_{\text {dic }}$ to multizone.

The multizone and CFD programs were coupled through the airflow rates or pressure drop at the interfaces. Through theoretical analyses, this paper has proved that the coupled program has a solution and the solution is unique with the three coupling methods.

This investigation also used the Scarborough criterion to evaluate the convergent performances and to analyze the stabilities of the three coupling methods during their iterative coupling processes. Method 1, which exchanges pressure boundary conditions between multizone and CFD programs, is unconditionally stable, while Methods 2 and 3 are conditionally stable. Two numerical experiments were conducted to demonstrate the theory: one was pressure gradient flow in an office suite and the other was cross ventilation in a four-zone building model. Although experimental data are either unavailable or limited for these two cases, numerical results show that the theory to be correct and valid. To further validate the numerical results, future studies of field measurements are required. 


\section{Acknowledgement}

This research was supported by U.S. National Institute of Standards and Technology (NIST) contract No. SB1341-04-Q-0771. The authors thank Dr. A.K. Persily and Mr. G.N. Walton from NIST for their contributions to the paper.

\section{References}

Bartak, M., Beausoleil-Morrison, I., Clarke, J.A.,et. al (2002) "Integrating CFD and building simulation", Building and Environment, 37, 865-871.

Beausoleil-Morrison, I. (2000) The adpative coupling of heat and air flow modeling within dynamic whole-building simulation, Ph.D. thesis, University of Strathclyde, Glasgow.

Bouia, H. and Dalicieux, P. (1991) "Simplified modeling of air movements inside dewelling room". In: Proceeding of Building Simulation 91 Conference, Nice, France, IBPSA (The international Building Performance Simulation Association), pp. 106-110.

Buhl, W.F., Erdem, A.E. et Winkelmann, F.C. (1993) "Recent improvement in SPARK: Strong componoent decomposition, multivated objects, and graphical interface". In: Proceding of Building Simulation '93 Conference, pp. 283-289.

Chen, Q. and Jiang, Z. (1992) "Significant questions in predicting room air motion". ASHRAE Transactions, 98(1), 929-939.

Chen Q. and Xu W. (1998) "A zero-equation turbulence model for indoor airflow simulation". Energy and Buildings, 28: 137-144.

Clarke, J.A. (1985) Energy simulation in building design, Adam Hilger, Bristol.

Clarke, J A, Dempster, W M and Negrao, C.O.R. (1995a) "The Implementation of a Computational Fluid Dynamics Algorithm within the ESP-r System". In: Proceedings of Building Simulation 95, Madison, pp. 166-175.

Clarke, J.A., Hensen, J.L.M., and Negrao, C.O.R. (1995b) "Predicting indoor air flow by combining network approach, CFD and thermal simulation". In: Proceedings of 16th AIVC Conference, pp. 145-53.

Clarke, J. A. (2001) "Domain Integration in Building Simulation". Energy and Buildings, 33(4), 303-308.

Emmerich, S. J. (1997) Use of computational fluid dynamics to analyze indoor air quality issue, National Institue of Standards and Technology Report NISTR 5997, USA.

Emmerich, S. J. (2001) "Validation of multizone IAQ modeling of residential-scale buildings: a review". ASHRAE Transactions, 107(2). 619-628.

Feustel H.E. (1999) "COMIS - An internatinal multizone airflow and contaminant transport model”. Energy and Buildings, 30, 3-18.

Gao, Y. and Chen, Q. (2003). "Coupling of a multi-zone airflow analysis program with a computational fluid dynamics program for indoor air quality studies". In: Proceedings of the 4th International Symposium on HVAC, Symposium on HVAC, Vol. 1, pp. 236-242, Tsinghua University, Beijing, China.

Grelat A. (1987) Approche des phenomenes de circulatiion et de stratification de l'air dans les locaux chauffes par le programme de simulation thermique multizone BILGA. CEBTP-EDF contract final report.

Haghighat, R., Lin, Y. and Megri, A.C. (2001) "Development and validation of a zonal model POMA", Building Environment, 36, 1039-1047.

Inard, C. (1988) Contribution a letude du couplage thermique entre un emetteur de chauffage et un local. Etudes experimentales en chambers climatiques, Ph.D Thesis, Lyon, France, National Institute of Applied Science (INSA). 
Jayaraman, B., Lorenzetti, D., Gadgil, A. (2004) Coupled model for simulation of indoor airflow and pollutant transport, Report LBNL-56667 for contract DE-AC03-76SF00098, Lawrence Berkeley National Laboratory, Berkeley, CA.

Ladeinde, F., Nearon, M. (1997) "CFD applications in the HVAC\&R industry", ASHRAE Journal, 39(1), 44-48.

Lebrun, J. (1970) Exigences physicologiques et modalites physiques de la climatisation par source statique concentree, Ph.D. Thesis, University of Liege.

Li, Y., Delsante, A. Symons, J.G. and Chen, L. (1998) "Comparison of zonal and CFD modeling of natural ventilation in thermally stratified building". In: Proceeding of Air Distribution in Rooms Conference, ROOMVENT'98, Stockholm, Vol. 2, pp. 415-422.

Lorenzetti, D. M. (2002) "Computational aspects of nodal multizone airflow systems", Building and Environment, 37, 1083-1090.

Mora, L. (2003a) Thermal and airflow precidtion in building by associating models with different levels of details within an objec-oriented simulation environment. Ph.D. thesis, Université de la Rochelle.

Mora, L, Gadgil, A.J. and Wurtz, E. (2003b) "Comparing zonal and CFD model precidtions of isothermal indoor airflows to experimental data", Indoor Air, 13, 77-85.

Murakami, S., Kato, S., Akabayashi, S., et al. (1991) "Wind tunnel test on velocity pressure field of cross-ventilation with open windows", ASHRAE Transaction, 97(1), 525-538.

Musser, A. (2001) "An analysis of combined CFD and multizone IAQ model assembly issues", ASHRAE Transactions, 107(1), 371-382.

Musy, M. (1999) Automatic generation of zonal models to perform airflow and thermal simulation in buildings (in French), $\mathrm{PhD}$ thesis, La Rochelle, France, LEPTAB University of La Rochelle.

Negrao, C.O.R. (1995) Conflation of computational fluid dynamics and building thermal simulation, $\mathrm{PhD}$ Thesis, University of Strathclyde.

Negrao, C.O.R. (1998) "Integration of computational fluid dynamics with building thermal and mass flow simulation", Energy and Buildings, 27(2), 155-165.

Nielsen, P.V. (1998) "The selection of turbulence models for preciction of room airflow", ASHRAE Transations, 104 (B), 1119-1127.

Patankar, S. V. (1980) Numerical Heat Transfer and Fluid Flow, McGraw-Hill Book Company, New York.

Ren, Z. (2002) Enhanced modeling of indoor air flows, temperatures, pollutant emission and dispersion by nesting sub-zones within a multizone model, Ph.D. thesis, The Queen's Universit of Belfast.

Ren, Z and Stewart, J. (2003) "Simulaing air flow and temperature distribution inside buildings using a modified version of COMIS with sub-zonal divisions". Energy and Buildings, 35, 257-271.

Sawachi, T., Narita, K., Kiyota, N., Seto, H., Nishizawa, S. and Ishikawa, Y. (2003) "Wind pressure and airflow in a full-scale building model under cross ventilation". In: Proceedings of the First International Workshop on Natural Ventilation, pp. 4-1 to 4-19, Tokyo, Japan.

Scarborough, J. B. (1966) Numerical Mathematical Analysis, Six Edition, The Johns Hopkins Press, Baltimore, MD.

Schaelin A., Dorer V., van der Mass J. and Moser A. (1993) "Improvement of multizone model predictions by detailed flow path values from CFD calculation", ASHRAE Transactions, 93-7-4, 709-720.

Srebric J., Chen Q., and Glicksman L.R. (1999) "Validation of a zero-equation turbulence model for complex indoor airflows", ASHRAE Transactions, 105(2), 414-427. 
Stewart, J. and Ren, Z. (2003) "Prediciton of indoor gassesous pollutant dispersion by nesting sub-zones within a multizone model", Building and Environment, 38, 635-643.

Walton, G. N. and Dols, W. S. (2003) CONTAMW 2.1 User Manual, NIST, Gaithersburg, MD.

Wurtz, E. (1995) Three-dimensional Modeling of Thermal and Airflow Transfer in Building Using an Object-oriented Simulation Environment (in French), Ph.D. Thesis, Paris, Ecole Nationale des Ponts et Chaussees.

Yuan, J. and Srebric, J. (2002) "Improved prediction of indoor contaminant distribution for entire buildings". In: Proceedings of American Society Of Mechanical Engineers, New Orleans, Louisiana, Vol. 258, pp. 111-118.

Zhai, Z. and Chen, Q. (2003) "Solution characters of iterative coupling between energy simulation and CFD programs", Energy and Buildings, 35(5), 493-505. 